\title{
Estudio mediante afm de estructuras de silicalita para la separación de gases
}

\author{
P. PRÁDANOS, L. PALACIO, A. HERNÁNDEZ, M. VILASECA*, J. CORONAS*, J. SANTAMARÍA* \\ Dpto. Termodinámica y Física Aplicada, Facultad de Ciencias, Universidad de Valladolid, Valladolid, España \\ (*) Dpto. Ingeniería Química. Universidad de Zaragoza, Zaragoza, España
}

\begin{abstract}
En este trabajo se han estudiado láminas de silicalita con aplicación en los procesos de separación de gases. Dichas láminas se han depositado mediante síntesis hidrotermal durante distintos tiempos y usando varias composiciones en el gel precursor. La deposición se hizo sobre un soporte de alúmina con crecimiento preferencial en dos direcciones. Finalmente las láminas se calcinaron a $753 \mathrm{~K}$ durante $8 \mathrm{~h}$ para eliminar el agente estructurante, usando velocidades de calentamiento y enfriamiento de $0.5 \mathrm{y} 1 \mathrm{~K} / \mathrm{min}$ respectivamente. Las superficies resultantes se han analizado mediante microscopía de fuerza atómica en modo de contacto-intermitente (tapping) con el fin de ver si efectivamente se ha conseguido depositar cristales de silicalita en las direcciones indicadas y seguir la evolución de crecimiento de los núcleos. Por otro lado, se ha determinado la estructura porosa de la silicalita comprobando que los resultados concuerdan con los obtenidos por otras técnicas.
\end{abstract}

Palabras clave: membranas cerámicas, Silicalita, Separación de Gases, Microscopía de Fuerza Atómica, Crecimiento de cristales.

\section{Study by afm of silicalite sctructure for gas separation}

In this work, we study films of silicalite crystals used in gas separation processes. These crystals were obtained by hydrothermal synthesis during different times and using different gel composition. They were deposited on an alumina support growing in two preferential directions. Finally, the material was placed in a stove at $480^{\circ} \mathrm{C}$ during $8 \mathrm{~h}$ in order to remove the structurant agent with heating and cooling rates of 0.5 y $2{ }^{\circ} \mathrm{C} / \mathrm{min}$ respectively. The resulting surfaces were analysed by atomic force microscopy (AFM) in tapping mode in order to notice the deposition of the silicalite crystals in the indicated directions, and also to distinguish the evolution of the nuclei growth. At the same time, the porous structure of silicalite has been determined, leading to results in good agreement with those obtained by other techniques.

Keywords: Ceramic Membranes, Silicalite, Gas Separation, Atomic Force Microscopy, Crystal Growth.

\section{INTRODUCCIÓN}

Durante años, el campo de aplicación de las zeolitas se ha extendido desde los procesos de separación (1) hasta los reactores de membrana (2), sensores (3) y otros microdispositivos (4). También se han llevado a cabo grandes avances en el caso de procesos de separación usando membranas de zeolita: se pueden encontrar, en la actualidad, algunas aplicaciones industriales, como en la deshidratación de compuestos orgánicos por pervaporación (5), la separación de trazas en gases (6) asimismo varios grupos muestran la posibilidad de separación de xilenos (7). Respecto a la síntesis de membranas de zeolita o, mas ampliamente, de láminas de zeolita, hay todavía bastantes cosas que no se entienden respecto a la interacción compleja entre la mezcla de la reacción y el soporte (8): la formación de una capa continua depende de varios factores, tales como la composición, el pretratamiento del soporte además de su localización en el reactor.

Por otra parte, la Microscopía de Fuerza Atómica (AFM) es una técnica de caracterización desarrollada en los últimos años. Ésta presenta un amplio abanico de posibilidades de desarrollo y aplicaciones en el campo de la observación microscópica y en la caracterización de muy diversas superficies, con la ventaja de que permite observar lo que ocurre a una escala de nanómetros (9), incluso en la superficie del cristal. Hay ejemplos de un gran número de zeolitas cuya estructura superficial ha sido analizada por esta técnica, (10-11). No obstante, la mayor parte de los estudios que se han realizado hasta ahora con AFM eran de cristales ya formados. En este trabajo se ha intentado hacer un seguimiento del crecimiento de los pequeños núcleos hasta la formación de los cristales de silicalita.

\section{MATERIALES Y MÉTODOS EXPERIMENTALES}

\subsection{Materiales}

Aquí, se ha estudio la formación de cristales tipo MFI de zeolita, a partir de pequeños núcleos implantados sobre un substrato. Las láminas de silicalita objeto de estudio se prepararon por síntesis hidrotermal sobre un soporte no poroso de alúmina de dimensiones 4 x $25.4 \mathrm{x}$ $0.635 \mathrm{~mm}$ (Rubalit 708S, $96 \% \mathrm{Al}_{2} \mathrm{O}_{3}$ de CeramTec) y tamaños medios de grano en el intervalo de 3 a $5 \mu \mathrm{m}$. Dos composiciones se usaron para el gel precursor, una de ellas (12) induce el crecimiento en la dirección c, mientras que la otra (13) da cristales orientados en la dirección b.

Los soportes fueron sumergidos en un autoclave de teflón, lleno del gel descrito y situado en un horno a $438 \mathrm{~K}$ durante tiempos desde 50 min hasta 8 horas. Para eliminar el agente estructurante, las muestras se calcinaron a $753 \mathrm{~K}$ durante $8 \mathrm{~h}$ con velocidades de calentamiento y enfriamiento de $0.5 \mathrm{y} 1 \mathrm{~K} / \mathrm{min}$ respectivamente.

\subsection{Métodos de caracterización}

Las superficies se caracterizaron mediante microscopía de fuerza atómica, donde el instrumento empleado era Nanoscope Multimode IIIA de Digital Instruments, trabajando en modo contacto-intermitente ("tapping"). El área barrida varió desde $125 \mu \mathrm{m}$ hasta $5 \mathrm{~nm}$ según zonas. Las imágenes fueron tratadas usando el software NanosScope V4.23 que permite analizar las imágenes haciendo filtrados para eliminar ruidos cuando ello sea necesario (14). 


\section{RESULTADOS Y DISCUSIÓN}

Se hicieron imágenes de muestras con direcciones de crecimiento c y b. En ambos casos, aunque el fin era obtener una capa continua de cristales de zeolita, la producción se paró en varias etapas con el fin de examinar los cambios que sufrían los cristales tanto en morfología como en tamaño en función del tiempo de síntesis.

En un primer paso (figura 1) lo que se observan son pequeños puntos (de tamaño inferior a $50 \mathrm{~nm}$ ) sobre el substrato; estos puntos son los núcleos de zeolita de tipo MFI formados sobre la superficie, proceso favorecido por la rugosidad de la alúmina. El substrato pronto empieza a verse cubierto por los cristales que van creciendo como se puede comprobar si analizamos las imágenes en el momento de la siembra y 50 minutos después (figura 2a y 2 b, respectivamente). En esos primeros estados el proceso es lento ya que la temperatura de comienzo del proceso es muy próxima a la temperatura ambiente y al principio la energía térmica se emplea en calentar el sistema hasta la temperatura de reacción (438 K). Esa lentitud del proceso facilita la detección de los núcleos.

No obstante y gracias a la potencialidad de la AFM es posible detectar los núcleos después de pasadas 8 horas, los cuales no se pudieron detectar con imágenes SEM realizadas con el fin de comparar. Esto se puede ver en la figura $3 b$, que corresponde a la imagen de contraste de fase de un cristal en orientación $\mathrm{b}$ después de 8 horas de síntesis. Con el fin de poder comparar como ha cambiado, en la figura 3a se muestra la imagen de fase de la misma muestra pero tras sólo 50 minutos de síntesis. Si de estas mismas muestras se presentan las imágenes de topografía en lugar de las de contraste de fase (figuras 4a y $4 b$ ), apenas se puede percibir la presencia de los núcleos, aunque sí es patente el cambio de forma y tamaño que han experimentado los cristales. Para estas mismas muestras, después de un tiempo de síntesis de 2 horas los cristales tienen un tamaño superior a $2 \mu \mathrm{m}$ (figura 5) y los núcleos de unos $170 \mathrm{~nm}$.

A medida que avanza el proceso los cristales de silicalita continúan creciendo hasta un tamaño de $5 \mu \mathrm{m}$ después de 8 horas. No obstante parece que, después de un cierto tiempo de síntesis, alguno de los nutrientes del gel se han consumido, no habiendo suficiente concentra-

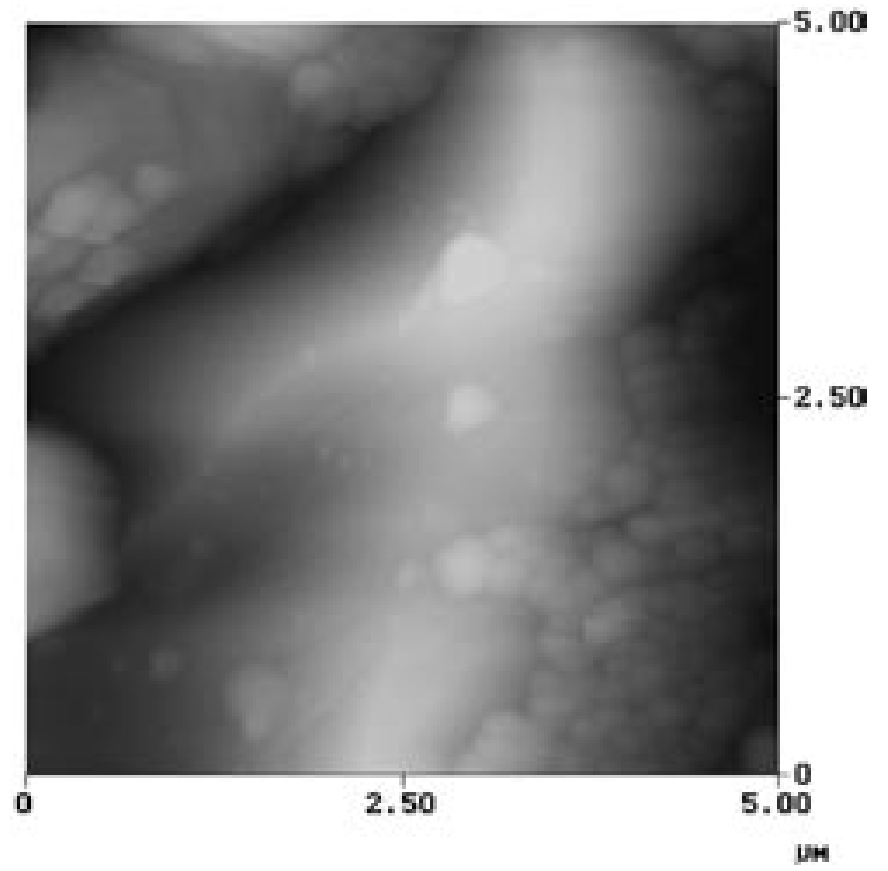

Fig. 1. Imagen topográfica por AFM (modo tapping) del soporte de alúmina con núcleos de zeolita en orientación c (instantes iniciales del proceso).

ción para una nucleación heterogénea y sólo es posible que los cristales se alarguen. Un hecho importante es que los núcleos siempre coexisten con cristales, de ahí que se pueda observar una estructura de 2 ó 3 niveles de cristales (figura $4 \mathrm{~b}$ ), con cristales de distintos tamaños.

Como último paso se estudió la estructura porosa de los monocristales de silicalita. Para ello se realizaron imágenes de áreas muy pequeñas (inferiores a $50 \mathrm{~nm}$ ) y después de un análisis de Fourier con el correspondiente filtrado del ruido generado en las imágenes se pudo comprobar que los poros en las dos direcciones del cristal tenían tamaños en torno a los $0,5 \mathrm{~nm}$, de acuerdo con los esperables para esa estructura (ver figura 6).
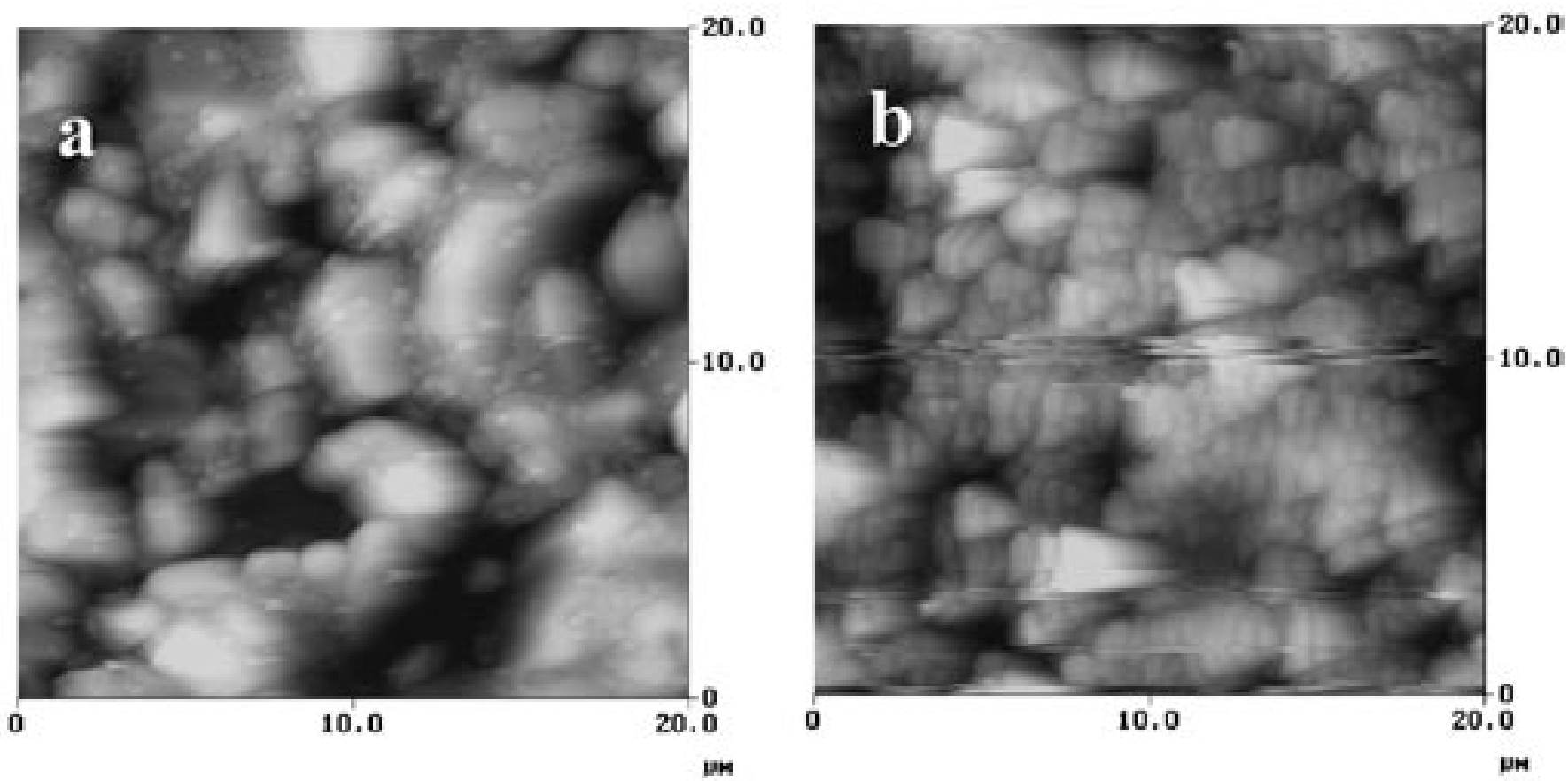

Fig. 2. Imágenes topográficas por AFM (modo tapping) de láminas de silicalita (orientación c) para tiempos de sintetizado de 0 y 50 minutos. 

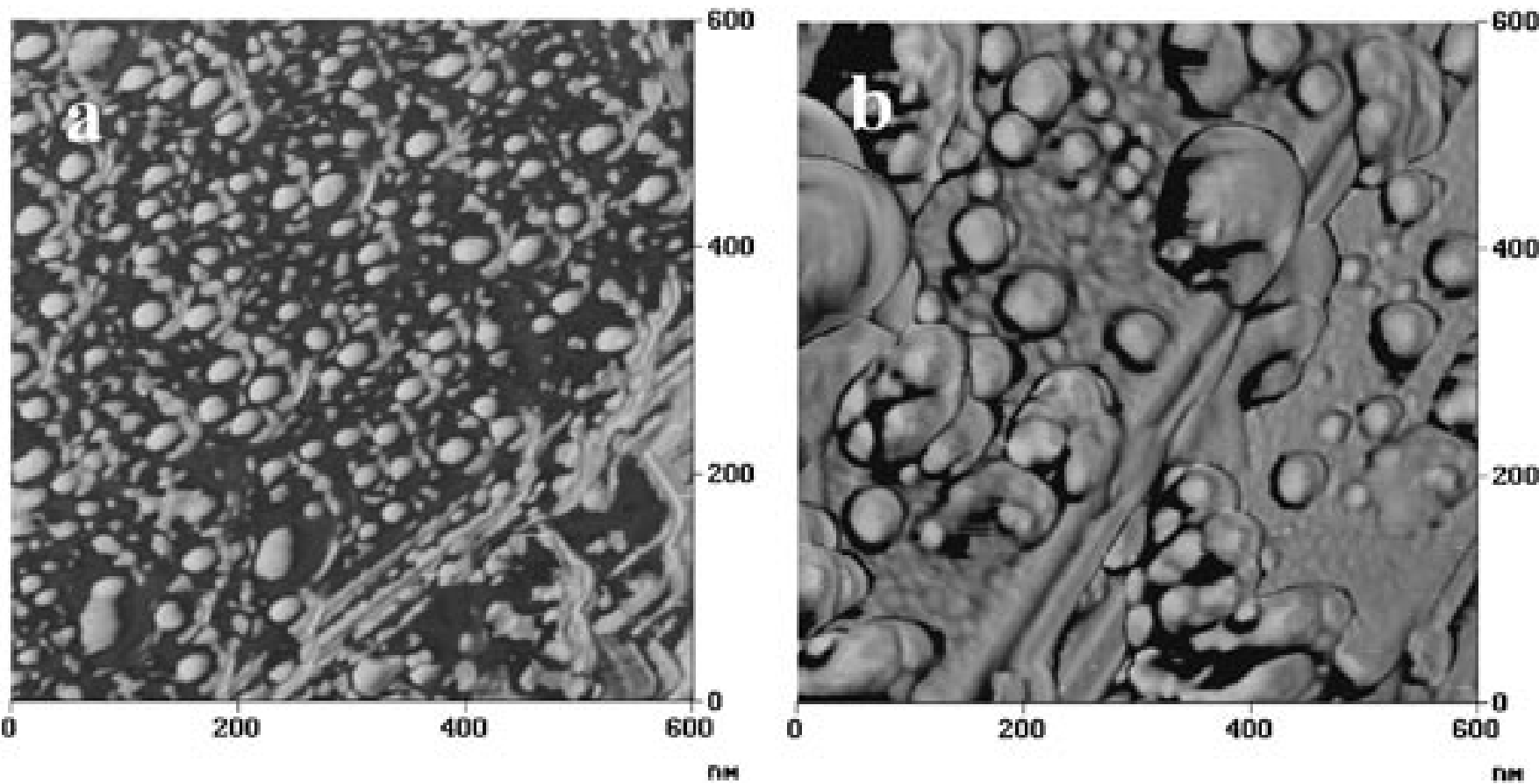

Fig. 3. Imágenes de contraste por fase de AFM (modo tapping) de láminas de silicalita (orientación b) para tiempos de sintetizado de 50 minutos y 8 horas.
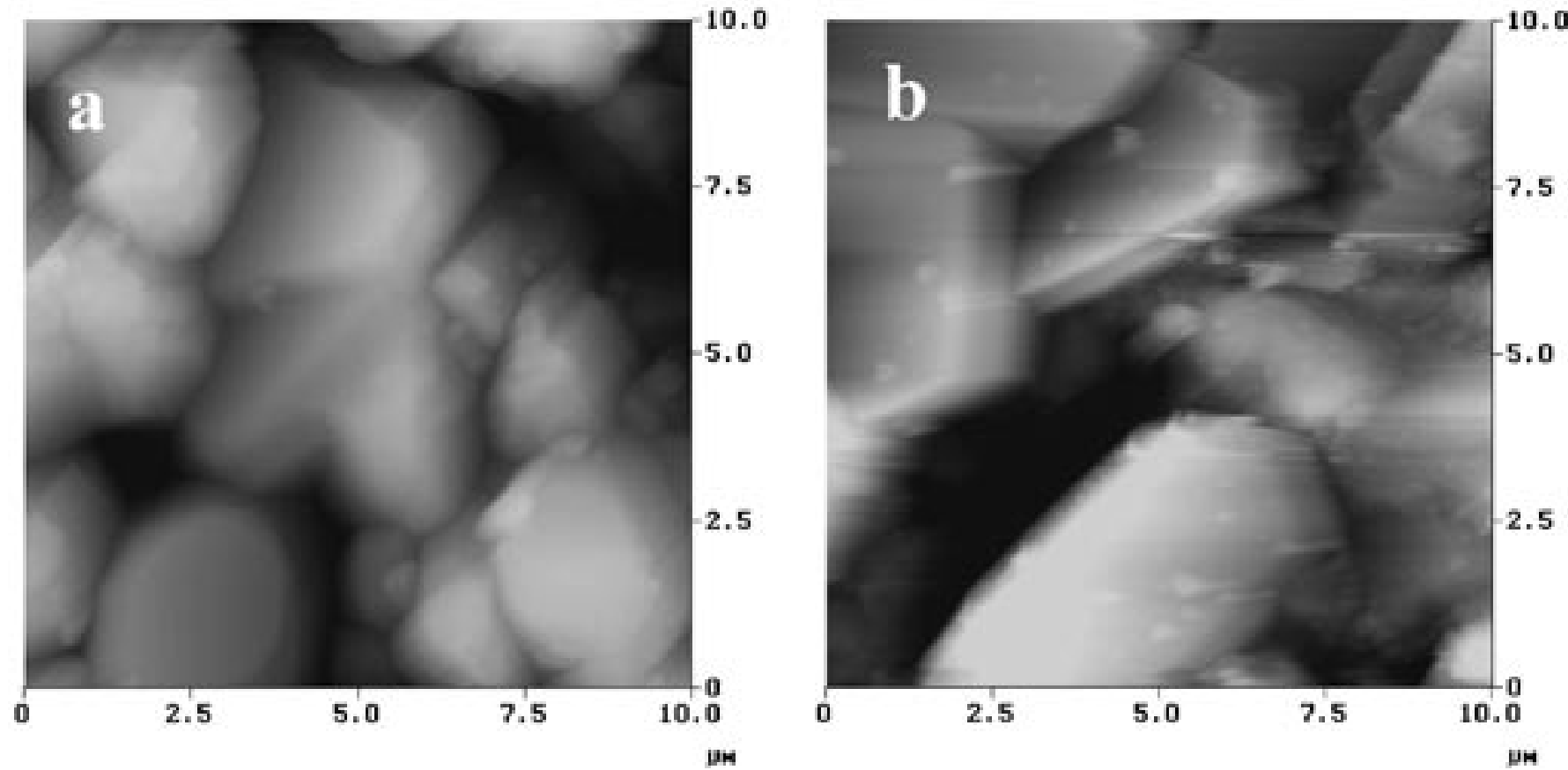

Fig. 4. Imágenes topográficas por AFM (modo tapping) de láminas de silicalita (orientación b) para tiempos de sintetizado de 50 minutos y 8 horas.

\section{CONCLUSIONES}

Como conclusión a los resultados e imágenes presentados podemos decir que:

- Efectivamente se ha conseguido depositar cristales de silicalita en las direcciones indicadas.

- Ha sido posible observar las distintas etapas de crecimiento de los cristales comenzando por pequeños puntos de tamaños inferiores a $50 \mathrm{~nm}$ que corresponden a los núcleos de cristalización de la zeolita.

- De forma comparativa se realizaron imágenes SEM de las mues- tras pero en estas no se llegaron a apreciar los núcleos de zeolita, lo cual confirma la potencialidad del AFM como técnica microscópica, llegando a la escala de nanómetros.

- En el análisis de la evolución del tamaño de los cristales se observa un aumento progresivo de éstos así como de los núcleos, aunque estos cada vez son más escasos. Para tiempos superiores a 4 horas en las imágenes de topografía ya no se distinguen los núcleos y hay que analizar las imágenes de contraste de fase. 


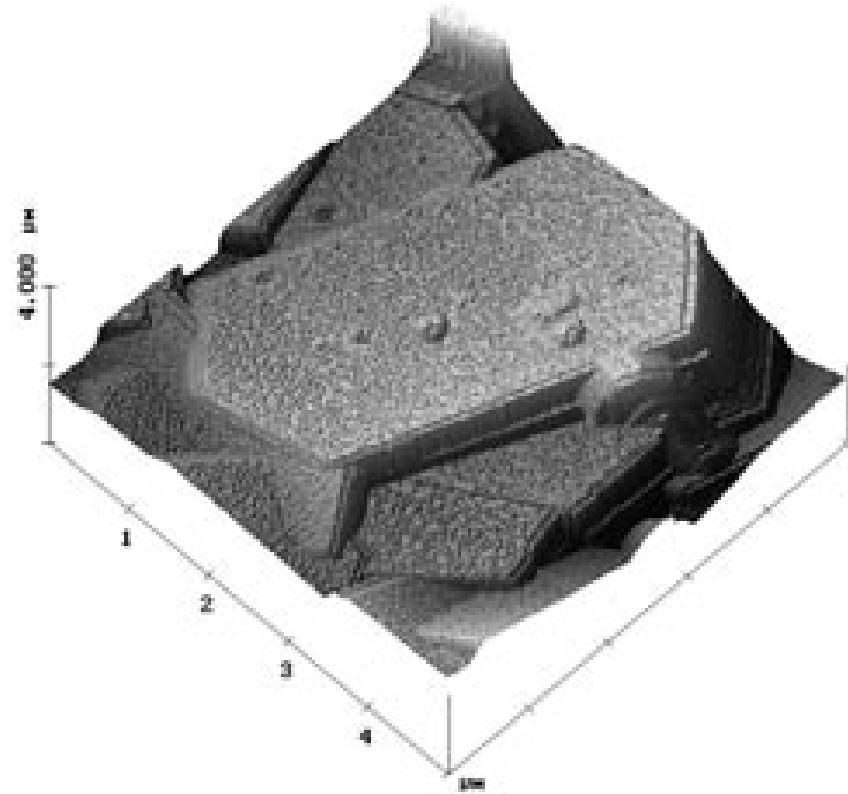

Fig. 5. Imagen topográfica en tres dimensiones por AFM (modo tapping) de lámina de silicalita (orientación b) para tiempos de sintetizado de 2 horas.

- Debido a la coexistencia de cristales y núcleos es posible observar una estructura de 2 ó 3 niveles de cristales con cristales de distintos tamaños.

- La estructura porosa de los monocristales de silicalita ha podido ser resulta mediante análisis de Fourier con el correspondiente filtrado del ruido generado en las imágenes resultantes. De este modo se ha comprobado que los poros en las dos direcciones del cristal están de acuerdo con los esperables para su estructura.

\section{AGRADECIMIENTOS}

Los autores agradecen la financiación a los siguientes proyectos de investigación: MAT1999-0989 del Plan Nacional de Investigación y Desarrollo y VA62-00B de la Junta de Castilla y León.

\section{REFERENCIAS}

1. J. Coronas, J. Santamaría, Catalytic reactors based on porous ceramic membranes, Catalysis Today, 51 (3-4) (1999) 377

2. E. Piera, C. Téllez, J. Coronas, M. Menéndez, J. Santamaría, Use of zeolite membrane reactors for selectivity enhancement: application to the liquidphase oligomerization of i-butene, Catal. Today, 67 (2001) 127.

3. Mintova S, Mo S, Bein T, Nanosized AlPO4-5 molecular sieves and ultrathin films prepared by microwave synthesis, Chem. Mater., 10 (12) (1998) 4030.

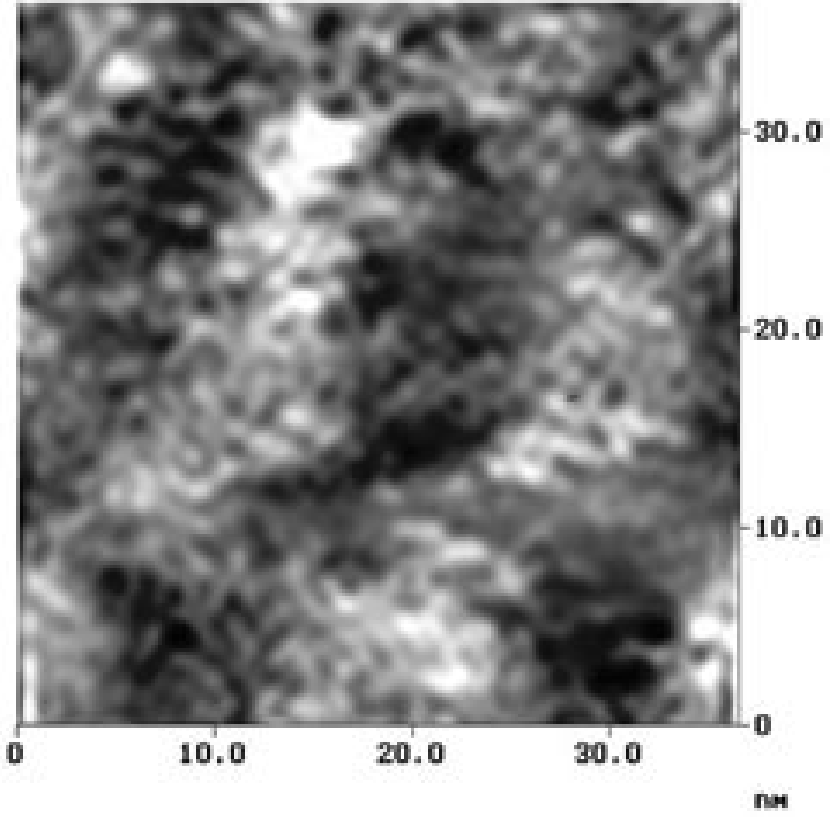

Fig. 6. Imagen topográfica por AFM (modo tapping) de lámina de silicalita (orientación b) resuelta por análisis de Fourier para tiempos de sintetizado de 2 horas.

4. Y.S.S. Wan, J.L.H. Chau, A. Gavriilidis, K.L. Yeung, Design and fabrication of zeolite-based microreactors and membrane microseparators, Micropor. Mesopor. Mater. 42 (2001) 157.

5. Y. Morigami, M. Kondo, J. Abe, H. Kita, K. Okamoto, The first largescale pervaporation plant using tubular-type module with zeolite NaA membrane, Sep. Pur. Tech., 25 (2001) 251.

6. E. Piera, C.A.M. Brenninkmeijer, J. Santamaría, J. Coronas, Separation of traces of CO from air using MFI-type zeolite membranes, J. Memb. Sci., 201 (2002) 229.

7. C.J. Gump. V.A. Tuan, R.D. Noble, J.L. Falconer, Aromatic permeation through crystalline molecular sieve membranes, Ind. Eng. Chem. Res. 40 (2001) 565.

8. R. Lai, Y. Yan, G.R. Gavalas, Growth of ZSM-5 films on alumina and other surfaces, Micropor. Mesopor. Mater., 37 (2000) 19.

9. G. Binnig, C.F. Quate, Ch. Gerber, Atomic force microscope, Phys. Rev. Lett. 56 (1986) 930

10. S.S. Ono, O. Matsuoka, S. Yamamoto, Surface structures of zeolites studied by atomic force microscopy, Micropor. Mesopor. Mater., 48 (2001) 103.

11. M.W. Anderson, J.R. Agger, N. Hanif, O. Terasaki, T. Ohsuna, Crystal growth in framework materials, Solid State Sci., 3 (2001) 809.

12. M. Lovallo, M. Tsapatsis, Preferentially oriented submicron silicalite membranes,AIChE J.,42 (1996)3020.

13. Z. Wang, Y. Yan, Controlling crystal orientation in MFI films by direct in situ crystallization, Chem. Mater. 13 (2001) 1101.

14. A. Hernández, J.I. Calvo, P. Prádanos, L. Palacio, A multidisciplinary approach towards pore size distributions of microporous and mesoporous membranes, en "Surface Chemistry and Electrochemistry of membranes, T.S. Sørensen (Ed.) Marcel Dekker, Inc. Nueva York (1999).

Recibido: 01.02 .03

Aceptado: 30.11 .03 